Invited paper

\title{
A SOCIAL VALUE SURVEY OF CHINA: \\ On the Change and Stability in the Chinese Globalization
}

\author{
Ryozo Yoshino*
}

This paper briefly reports on a social value survey of China conducted during 2001 fall-2002 winter as part of our cross-national comparative study. The survey areas are the central parts of Beijing and Shanghai. The data show the change and stability of traditional social values of Chinese in a new social system under construction.

Our past studies have confirmed that people's attitudes and values on political and economic systems may change in a short term whereas the interpersonal relationships are relatively stable over time. China, however, may be in a time of transition on interpersonal relationships as well as international relationships. For example, although the family is still an important core as the social unit in China, the style of family may be changing in the younger generation. Our data show some differences between the total samples and the younger elite groups in those cities in China. This may present some clues to foresee the near-future of China.

\section{Introduction-Some History on Cross-National Survey of ISM-}

The main objective of this paper is to present a brief report on a Chinese value survey conducted during 2001 fall - 2002 winter, as part of our cross-national comparative survey over some decades. The survey areas were the central parts of Beijing and Shanghai. These two areas may not represent the whole country, but they are two of the most important cities to show the rapid social change and the international relationships between China and the other countries in the time of globalization. The background and significance of this study is as follows.

The last two decades have witnessed a rapid global change, which lead us the reconstruction of social order for the next age. In this global reconstruction, we are facing military or political conflicts occurring in certain local areas, which are potential threats to all the peoples on the earth. Each nation or race has its own culture, social value and way of thinking, which underlie its system of economy, politics and social life. Therefore, the mutual understanding of each nation or race is the key to the peaceful development of the world in the time of globalization.

The Institute of Statistical Mathematics (ISM) has been conducting a longitudinal nationwide social survey on the Japanese national character ("Nihon-jin no Kokumin-sei Chosa") every five years since 1953 (Hayashi, 1992; Mizuno et al., 1992). Here the term "national character" means the characteristics shown in people's response patterns to the questionnaire of survey (cf. Inkeles, 1997). The question items cover various aspects of people's opinions about their social attitudes, values, and way of thinking. This survey

Key Words and Phrases: China, cross-national comparative survey, cultural manifold analysis, CULMAN, globalization, national character, science of data, social values, super-culture model, pattern analyses, trust

* The Institute of Statistical Mathematics, 4-6-7 Minami-Azabu, Minato-ku, Tokyo 106-8569, Japan. E-mail: yoshino@ism.ac.jp 
was started to clarify the Japanese national character in the post-World War II, and it was closely related to the establishment of public opinion survey system based on a statistical sampling theory. This statistical and sociological survey must have been important at the time when Japan was expected to change from a military regime to a democratic country (Yoshino, 2003). Although it was originally not intended as a time series survey because nobody expected a short-term change of national character, the second survey conducted in1958 showed some significant changes on certain items. This finding confirmed the importance of longitudinal survey to see the stability and change on the national character. And this survey stimulated many countries to start carrying out similar time series surveys.

Since 1971, this survey has been extended as a cross-national comparative study for more advanced understanding of the Japanese national character (Hayashi, 1973). The focus of cross-national survey is the comparison of peoples' social values, their ways of thinking and their feelings, and the items of our questionnaire cover cultural identities, economy, interpersonal relationships, leaderships, religious attitudes, social values on science and technology, politics, social security, freedom of speech, etc. Although certainly those items are more meaningful in a cross-national comparative framework to establish more reliable statistical pattern on people's responses, the cross-national comparison involves its own problems on comparability due to different sampling methods and translation across countries. As our approach towards the problems, for examples, Hayashi [2001] and Yoshino [2001] developed a certain methodology called "science of data". Briefly, a core of statistical analysis of science of data consists of certain multi-dimensional analyses (e.g., Hayashi [1992]'s quantification method III or Yoshino [1992a]'s Super-culture model) on a set of items, rather than by analyzing items separately, and obtained cross-national patterns that are stable over some changes of translation or sampling methods.

In our search for conditions which can guarantee meaningful cross-national comparability of social survey data, we decided that beginning our study by a comparison of two nations (or races) which have some similarity, e.g., in their racial origin or language, would have more meaning than attempting to begin from a comparison of two totally different nations (or races). Therefore, our task is to investigate in what aspects and to what degree the nations (or races) involved is similar or dissimilar to each other.

Our cross-national survey was started with the comparison of the Japanese in Japan and Americans with Japanese ancestry in Hawaii. Table 1 is a partial list of our past cross-national surveys since 1971. Some of those nations or areas share certain common features such as race or language. Therefore, they provide meaningful links for comparison to show what aspects and to what degree certain pairs of nations are similar or dissimilar to each other. Extending the chain of links, eventually we will be able to obtain a chain of global cross-national comparison. (See Fig. 1 for an illustration). Therefore we call our research methodology cultural linkage analysis (CLA) for cross-national comparison.

In the development of CLA, we have come to focus on the main components: crossnational comparative link, time series comparative link, and item-sets comparative link. Furthermore, introducing hierarchical structures into these three types of link structures, we have a sort of cultural manifold where each chart may correspond to a region, a 
Table 1: List of Our Past Surveys on National Character.

1953- Present (every five years). Japanese national character survey Japanese Americans in Hawaii

1978 Honolulu Residents (including Japanese American), \& Americans in the USA (mainland).

1983 Honolulu Residents (including Japanese American)

1987 Britain, Germany \& France

1988 Honolulu Residents (including Japanese American) Americans in the mainland of U.S.A, the Japanese in Japan

1991 Japanese Brazilians (JB) in Brazil

1992 Italy

1993 The Netherlands

1998 Americans with Japanese ancestry in the West coast of U.S.A.

1999 Honolulu Residents in Hawaii

(All these surveys were based on statistical random sampling data. See Yoshino (2005b)

for more recent surveys.)

time, or a topic. We now call the methodology of analysis based on the framework CULMAN (cultural manifold analysis). (See Yoshino, 2005a, for the explanation of CULMAN.)

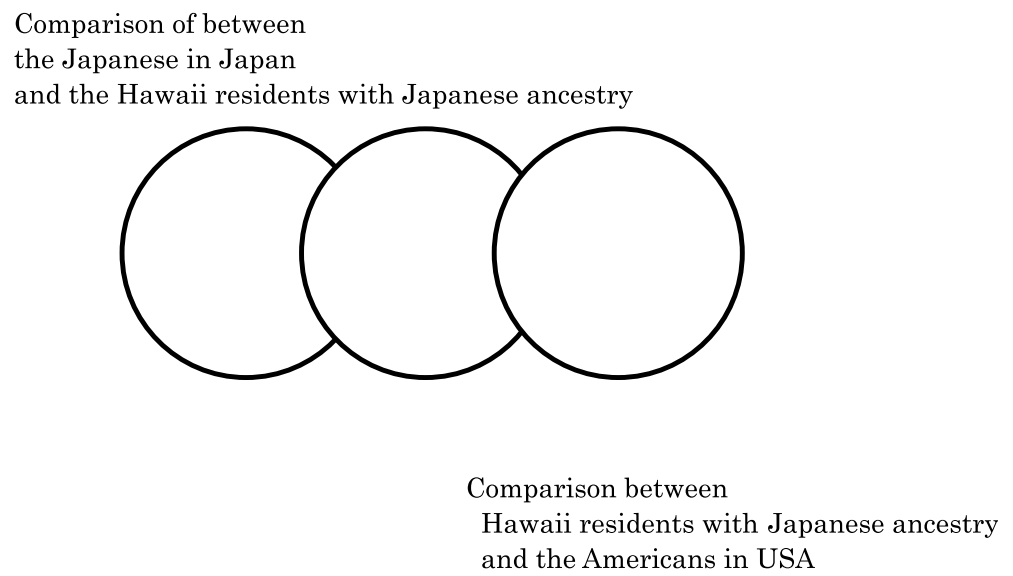

Figure 1: Cultural Linkage Analysis: Extending link of local comparison, we may eventually get a global chain of comparison on peoples' social attitudes and values.

Once our methodology of cross-national comparison is established, a set of survey data may yield psychological distances evidenced in certain response patterns between countries. Our final goal is to develop a behavior-metric study of civilizations through survey data as a field of social science. For more details of the development of CLA and CULMAN as a science of data, see Hayashi (2001), Hayashi et al. (1998), and Yoshino (1995, 2001, 2005a).

In this paper, I will briefly report on our survey in China, which is in a transitional stage from the socialist system to a new system under construction. Once upon a time, Weber (1904-05) argued that the Asian countries, particularly China could never develop 
capitalism because they lacked spirit such as that of Protestant ethics, and moreover, Chinese Confucius philosophy looks down diligence (hard working). But the economic success of Japan gave a counter-example against his argument. Morishima (1984) attempted to explain the Japan's success by the Japanese style of Confucius teaching (the emphasis on punctuality, diligence, and observance of promise) functioned equivalently to the Protestant ethics. But, then, the economic success of NIES including non-Confucius and non-Protestant countries gave other counter-examples. Until the former half of 1990s, many Asian countries have developed in a way to regard Japan as a model of the Asian modernization. Recently China is presenting another counter-example. We now have more advantage to consider the old problem on relationships between social values and social systems (cf. Inkeles, 1997) than before, because we witnessed the rapid changes of many countries in the aftermath of cold war. In his cross-national comparison and longitudinal studies on national character, Yoshino (2003) showed that peoples' attitudes and social values may show short-term changes on economic and political conditions but that those on interpersonal relationships are relatively stable.

In this paper I will show some clues on a possible direction of future China in order to develop constructive arguments for the peaceful development in the Asia. (For the detailed statistics and the methodology of the survey, see ISM Research Report No. 89 [Zheng, 2002] \& No. 90 [Zheng, 2003]; Zheng \& Yoshino, 2002, 2003). In Section 2, after briefly reviewing the general background of China, I will explain some aspects of their social values. In Section 3, I will explain some topics separately: family, traditional values, senses of satisfaction with respect to life, social environment, family, and health. In Section 4, I will focus on, among others, people's sense of trust. In Section 5, finally, I will briefly comment on the future development of comparative framework of social survey, namely, a hierarchical cultural manifold.

\section{Overview of the Chinese Social Values}

\subsection{General Background of China}

Firstly, I will explain on demographic statistics of our samples as follows (see Table 2). The samples were chosen in the 3 -stage random sampling (area sampling) for the faceto-face interview survey, according to the distribution of population in the census data. At each sampling point, a certain number of households were randomly chosen and one respondent was chosen at each of the households by Kish method (a sort of birthday rule). The valid questionnaire returns were 1087 in Beijing and 1042 in Shanghai, and the return rates were $43.9 \%$ and $56.8 \%$ respectively. We should be careful about possible biases due to the low return rates in the analysis of the response data. (Unfortunately, low return rates are nowadays common in urban surveys all over the world. People use quota-sampling or random route sampling in USA and Europe in order to obtain certain number of respondents previously planned, but those methods do not provide us with the exact questionnaire-return rates nor the estimate of sampling errors based on a rigorous random sampling theory. Because one of the most important objectives of our survey is 
Table 2: Demography of the Populations and the Samples (\%).

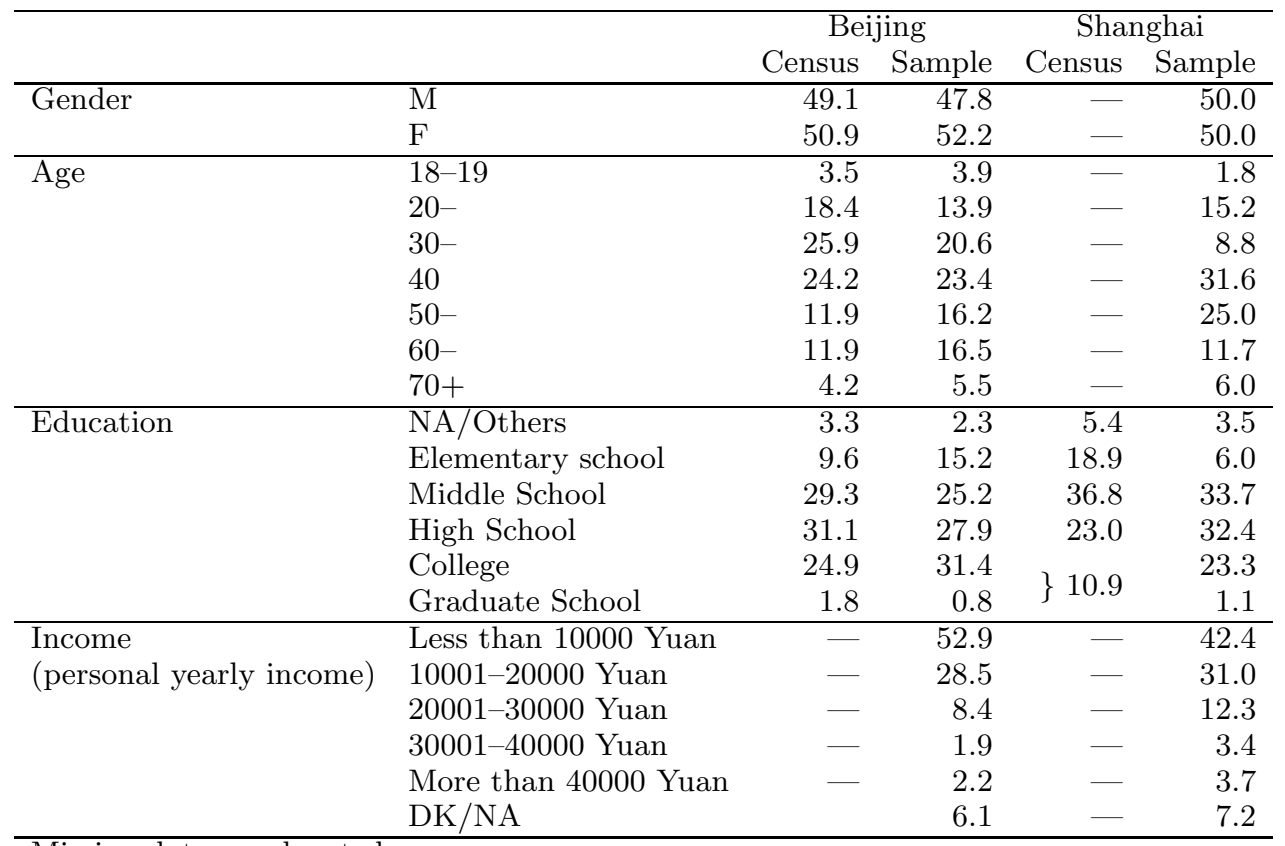

Missing data are denoted as -.

to investigate possibilities of the statistically rigorous methods of random sampling, we are doing our best to use certain probabilistic random sampling whenever possible.)

Education. Roughly, in each city, one third of our sample is elementary school or middle school graduates, another one third is high school graduates, and the remaining one third is graduates of college or graduate school. The education level of our samples is higher than is expected in the population. This may be the case because our survey areas are restricted to the central parts of those cities. It is said that people are becoming to emphasize the importance of education after 1992, particularly in the urban areas. This may be closely related to Mr. Deng Xiao Ping's new policy presented as a lecture at the southern area in 1992, which brought great social changes including education. Although highly educated people were politically compressed in the Mao's reign, people have started to invest more and more money to their child education in the past decade, because they now expect the higher education to be linked to economic and political power in today's China. For example, the leaders had to be either the farmers or laborer in the Mao's reign, but now many of new leaders of the government and the Party in China are college graduates. Furthermore the government is calling back Chinese students who got Ph.D. degrees in USA or Japan, preparing certain high rank positions and high salaries for them.

Some people say that China has already become a capitalist country, probably more capitalistic than Japan or USA in a sense. On the other hand, this rapid social change is producing a social confusion in China. Incredibly, for example, some people buy the certificate of college degree by money behind the scene. (Their traditional technology of copying has been useful in creating various fine arts over centuries, but it is now causing 
international issues on copyright.)

Income. Note that the self-report income of our data might show only part of their real income. Their real income might be higher because side business is popular now in those cities and some people spend more energy and time for their side business to gain much more than in their regular jobs. Tax and unemployment are new concepts to the today's Chinese.

\section{Social class.}

As for the self-reported social class, the response pattern is almost the same as that of Japan. At this point of analysis, I am not sure whether this shows that the economic power of China (Beijing \& Shanghai) has grown up to the level of Japan, or whether the patterns of self-perception of one's social class are almost the same across countries. (The pattern of Japan on this matter has been almost the same, at least, in the past decades in spite of the rapid changes. This is the case with the pattern of USA too.) It would be interesting to investigate a possibility of, so-to-speak, the principle of social relativity on class perception (See the comparative data of Hayashi et al., 1998).

Secondly, in order to understand the survey results, I will explain about some basic social values of Chinese. It is often pointed out that Chinese way of thinking is characterized by a bivalent frame of Lawyer's philosophy (worldly wisdom) in the deep structure and Confucius Ethics on the surface. This may be analogous to the Japanese way of thinking, i.e., honne (true opinion) and tatemae (one's public position). Later this will be exemplified in an analysis of their response data.

Also, it is well known that the family tie is remarkably strong in the Chinese society including the oversea Chinese. Fukuyama (1995) said that China developed the society of strong family ties because of the strong political centralization in the long history as in Italy or France, and that they did not necessarily develop intermediate social groups between families and the State. He said also that it was closely related to their low trustfulness and eventually to economic inefficiency.

An intermediate social group of China, business or underground group, takes frequently a form of quasi-family or an extended family such as "Ban (a sort of bond)". It is important to note that Chinese family and their quasi-family bonds are in horizontal relationships whereas the Japanese style is in a vertical hierarchical system.

Incidentally, our data show the number of family members is 2 or 3 in some $70 \%$ of all families in Beijing and Shanghai. The "one-child policy" has been observed, but now it is said that more and more people are ready to pay the penalty in order to have more children.

It is pointed out that there are some disparities of social values between the three generations: the senior generation before the Great Cultural Revolution, the generation that had grown up in the middle of the Revolution, and the younger generation after the Revolution (See Sengoku \& Qian, 1992). Their relationships are complicated. For example, the younger generation is more anti-Japanese than the senior generation who has directly experienced hardships during WWII. This is because of their educational system and mass communication in China on their policy of "anti-Japanese military." And the insufficient mutual understanding on this matter has been occasionally causing conflicts 
and confusion between China and Japan up to today, although both countries seem to have started their efforts to overcome the conflict.

As for the regional differences between Beijing and Shanghai, these two big cities are frequently contrasted in many aspects. Among others, Beijing is more political oriented whereas Shanghai is more commercial oriented. Shanghai has been an international commercial city over centuries. On the other hand, people of Beijing as the capital of China have been more concerned with domestic and international politics. For example, the former Prime Minster Zhu Rongji started fighting against unfairness and injustice of their political and economic systems for the establishment of more trustful China. (This was paralleled with their efforts for the participation of WTO or then for the fight with SARS.)

Finally it is pointed out Chinese and Americans are similar to each other in their human nature, such as individualism. But different combinations of individualism and sense of interpersonal relationship might yield different social atmospheres. Our data may provide us with some clues as to the old problem concerning the personality and the social systems (Inkeles, 1997).

Because we have cross-national comparative data in the previous studies of seven countries (Japan, USA, and five European countries) (Hayashi et al., 1998), we utilize the data for the analysis of China in comparison mainly with the seven countries. Although we cannot disregard the time difference of surveys (USA, UK, France and FRG in 1987, Japan in 1988, Italy in 1992, \& Holland in 1993), we can use the data of those countries in order to locate the current China in the comparative frame of the seven countries.

Now some topics are summarized separately in the following sub-sections.

\subsection{Family Tie}

As many writers have emphasized, the style of family is a key to the understanding of national differences of interpersonal bonds. As mentioned before, it is known that the family tie is remarkably strong in Chinese. Here we will consider some items related to family or family life in order to investigate the stability of traditional values as well as the rapid change of modern Chinese.

The stability of social values on family is seen on several items. For example, the majority chose the category that "family problems should be solved within one's own family (some 80-90\%)," and the category that "home is the only place where I can relax and feel good (some 70\%)" (the rate is almost the same as those of the seven advanced industrial countries: Japan, USA, UK, France, \& West Germany. See Hayashi et al. [1998]). These may be linked to the universal function of family as a basic social unit. As for the role of men and women in families, the majority thought that men and women should share their works in their families. (Note that, until some years ago, men and women had been supposed to work equally in the socialist country, and certain children care system was prepared for working parents. This is not necessarily the case with Japan.) For another example, the majority chose to "pride in ancestor." However, the rate of respondents who want to abolish such an old value" is $23 \%$ in Beijing and $8.5 \%$ in Shanghai (Table 4). This may show a possible change of their traditional value. It will be explained more in next 
Table 3: Items on Family (\%)

\begin{tabular}{|c|c|c|c|c|}
\hline & \multicolumn{2}{|c|}{ Beijing } & \multicolumn{2}{|c|}{ Shanghai } \\
\hline & *Total & $* *$ Elite & *Total & $* *$ Elite \\
\hline \multicolumn{5}{|l|}{ Respect ancestor } \\
\hline more than the average & 43.3 & 30.3 & 25.9 & 15.3 \\
\hline less than the average & 8.5 & 15.4 & 13.3 & 26.1 \\
\hline the average & 42.4 & 43.9 & 52.9 & 50.3 \\
\hline \multicolumn{5}{|l|}{ Adopt a child for your family line? } \\
\hline desirable & 21.6 & 14.5 & 19.7 & 12.7 \\
\hline meaningless & 10.9 & 13.2 & 24.7 & 28.0 \\
\hline undesirable & 44.9 & 44.3 & 24.3 & 28.7 \\
\hline it depends & 17.9 & 21.5 & 25.7 & 24.2 \\
\hline \multicolumn{5}{|l|}{ Satisfaction with family } \\
\hline satisfied & 52.3 & 45.6 & 35.9 & 36.9 \\
\hline fairly satisfied & 38.7 & 44.7 & 51.0 & 54.1 \\
\hline neither & 3.6 & 3.9 & 8.6 & 6.4 \\
\hline fairly dissatisfied & 3.5 & 4.4 & 2.8 & 2.5 \\
\hline dissatisfied & 1.6 & 0.9 & 0.9 & 0.0 \\
\hline \multicolumn{5}{|l|}{ A family trouble shooter is } \\
\hline within family & 89.1 & 89.9 & 78.3 & 75.8 \\
\hline a senior & 5.5 & 6.6 & 12.4 & 19.1 \\
\hline a neighbor & 1.3 & 0.4 & 5.8 & 2.5 \\
\hline a chief in workplace & 0.5 & 0.4 & 0.7 & 0.0 \\
\hline the court & 1.1 & 0.9 & 1.3 & 1.9 \\
\hline \multicolumn{5}{|l|}{ Home is the only relaxing place? } \\
\hline Yes & 76.4 & 68.0 & 69.9 & 63.7 \\
\hline No & 19.0 & 25.0 & 24.7 & 31.2 \\
\hline \multicolumn{5}{|l|}{ Marriage should be permanent? } \\
\hline permanent & 19.0 & 7.0 & 15.1 & 6.4 \\
\hline broken under serious problems & 46.8 & 48.2 & 52.6 & 45.9 \\
\hline broken by agreement & 30.6 & 43.4 & 27.1 & 45.3 \\
\hline \multicolumn{5}{|l|}{ House keeping } \\
\hline it is women's work & 3.6 & 1.3 & 5.4 & 5.1 \\
\hline some of the work is women's & 15.8 & 23.7 & 35.1 & 31.2 \\
\hline men and woman should share & 79.3 & 73.7 & 57.2 & 62.4 \\
\hline \multicolumn{5}{|l|}{ Child-raising } \\
\hline let them have their own ways & 52.5 & 75.4 & 55.9 & 72.6 \\
\hline put them under parental control & 43.5 & 20.2 & 38.8 & 23.6 \\
\hline \multicolumn{5}{|c|}{$\begin{array}{l}\text { 1) *Total shows the response percentage to each category of the total } \\
\text { sample in Beijing and in Shanghai, respectively. }\end{array}$} \\
\hline \multicolumn{5}{|c|}{$\begin{array}{l}\text { 2) } * * \text { Elite shows the response percentage to each category of the } \\
\text { younger elite (those who are } 44 \text { years old or younger, with high level } \\
\text { education (college or graduate school). These notations are the same } \\
\text { all through the tables in this paper. }\end{array}$} \\
\hline
\end{tabular}

sub-section.

A rapid change of the current China may be seen on the items related to marriage life: some $46-53 \%$ of people "admit divorce whenever they see serious problems." The response rate of that category of China is larger than in any of the seven countries previously surveyed. This is clearly linked to the rapid increase of divorce rate in Beijing and Shanghai these years (Recently the law has been changed, so that they can now divorce without consent of the bosses in their workplaces). Besides the rapid increase of crime 
rate is also seen in these big cities. These changes seem to parallel with their development of capitalism (One may remember that Fukuyama [1995] utilized the divorce rate and the crime rate as indices of distrust). This may be contrastive to USA, where the crime rate had been increasing up to the 1980's but it became lower in the 1990's when they saw the recovery of economy and enjoyed the prosperity that they had never had before. In the transition from the socialist system to a capitalist system (or open market system), China must be facing a social confusion for a certain period of time.

There may be some significant differences between Beijing and Shanghai on the items related to "respect of ancestor": the response pattern of people of Shanghai is similar to those of French and Japanese Americans in Hawaii (1999 survey) (Yoshino [Ed.], 2001b). The rate of respondents who would "adopt a child in order to continue one's family line" if he/she has no child is low in Shanghai. This might show a symptom of collapse of traditional value on family which must have been based on the preservation of family line. Or it might be the case that such a traditional value has not been respected in the international city Shanghai than in the other parts of China. The latter possibility might be interesting, but we do not have a longitudinal survey data to investigate on this matter.

As for child education, the rate of respondents who chose "to let children have their own ways" is more than $50 \%$ whereas the rate to "put them under parental control" is about $40 \%$ in both cities.

Fig. 2 shows the result of Hayashi's quantification method III (a sort of factor analysis for categorical data) applied to the response data on the items concerning their sense of satisfaction with respect to family, life, living environment, and health. Although it is said that China, France and Italy are similar to each other in their strong family bonds, this figure shows that France can be distinguished from Italy and China with respect to their satisfaction of family. That is, the ways of family bonds may distinguish France from Italy and China (Fukuyama, 1995, Chapter 11).

Fig. 2 shows also that the categories "very satisfied" and "fairly satisfied" of all items made a cluster whereas the categories "fairly dissatisfied" and "dissatisfied" were scattered along one item by another. This may remind you of the beginning of "Anna Karenina" by L. Tolstoy [1878], as follows.

"All happy families are more or less like one another; every unhappy family is unhappy in its own particular way. The Oblonsky household was in a complete state of confusion...." (Quote from the translation by Townsend [1958].)

Besides, Table 3 shows some differences between Beijing and Shanghai as well as between the total samples and the younger elite groups defined as those people of 44 years old or younger, with high level education [college or graduate school]. Note that the definition considers that the Great Proletarian Culture Revolution started in 1966 and ended in 1977, during when people lost a chance of college education. Overall, the younger elite groups in these cities seem more liberal than the total samples.

\subsection{Traditional Values}

This survey covered the items on ten Chinese traditional values a) to j) as follows. 


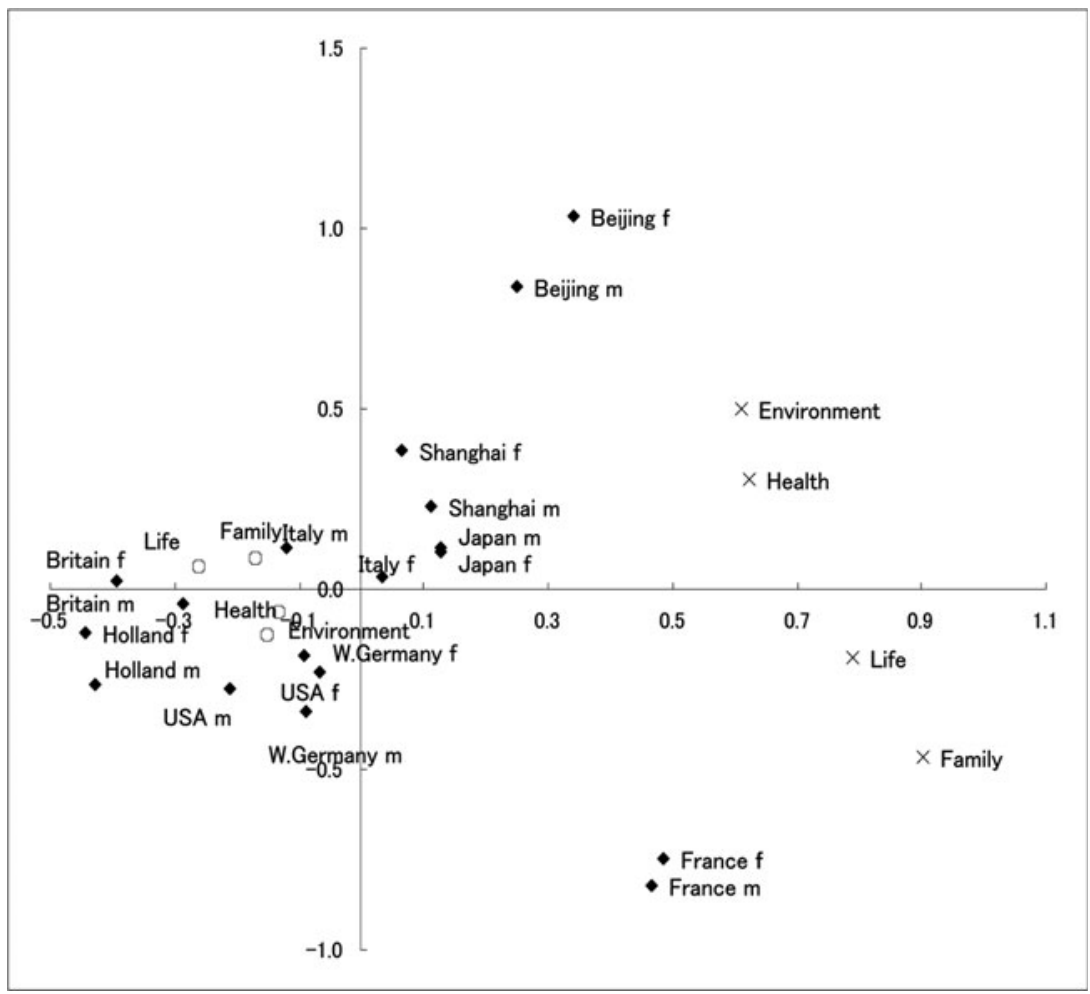

Figure 2: Satisfaction with Living Environment, Family (Home), Health and Daily Life. All the satisfied people are similar, whereas the dissatisfied people show various patterns along each own item. (O denotes the combined categories of "very satisfied" \& "fairly dissatisfied" and X denotes the combined categories "fairly dissatisfied" \& "very dissatisfied.") In this cross-national comparison, the France is far away from China (Beijing \& Shanghai) and Italy with respect to the dissatisfaction on Family. The differences between male $(\mathrm{m})$ and female (f) are much smaller than the cross-national differences.

(Note that many of these are typical values of the Chinese or the Asians, therefore, it is sometimes difficult to express the exact meaning in English. Therefore the English words mentioned below should be considered as tentative translation. Also note that some categories were re-grouped to obtain more stable response patterns in the data analysis.)

a) Self-protection for one's own interests.

b) Moderation (golden mean) and harmony with others

c) Women's obedience (women should be obedient to her father before marriage, her husband when married, and her children after her husband's death), four virtues, distinction between men and women, and respect to senior people

d) Diligence and frugality

e) Farmers should be respected more than merchants.

f) Loyalty to the State

g) Parental love, filial piety, offspring's prosperity, and glory to ancestors.

h) Tolerance, propriety and deference, humanity, justice and virtues, pay for one's obli- 
Table 4: Chinese Traditional Values. "Of the following elements of traditional culture, in your opinion which do you feel proud of, and which should be discarded?"

Each figure shows the percentage of those who answered "I am pride of it" minus the percentage of those who answered "it should be discarded" in each item (a to j).

\begin{tabular}{|c|c|c|c|c|}
\hline & \multicolumn{2}{|c|}{ Beijing } & \multicolumn{2}{|c|}{ Shanghai } \\
\hline & Total & Elite & Total & Elite \\
\hline a) self-protection for one's own interests & -32.5 & -35.9 & -4.6 & -11.4 \\
\hline b) moderation (golden mean) & 35.1 & 32.8 & 31.3 & 31.2 \\
\hline c) women's obedience \& four virtues & -17.9 & -37.7 & -33.0 & -42.7 \\
\hline d) diligence \& frugality & 95.0 & 90.8 & 83.3 & 73.3 \\
\hline e) Farmers are more important than merchants. & -33.8 & -55.2 & -34.1 & -55.4 \\
\hline f) loyalty to the State & 83.8 & 76.8 & 69.6 & 56.0 \\
\hline g) parental love, filial son, glory to ancestors, etc. & 23.1 & 11.9 & 51.3 & 35.7 \\
\hline h) tolerance, propriety \& deference, etc. & 86.1 & 78.5 & 80.1 & 72.0 \\
\hline $\begin{array}{l}\text { i) Never impose on others what you do not want to be } \\
\text { imposed. }\end{array}$ & 41.2 & 52.7 & 42.4 & 51.6 \\
\hline j) Be egocentric to avoid a Heaven's punishment. & -65.1 & -64.1 & -62.9 & -66.3 \\
\hline
\end{tabular}

gation

i) Never impose on the others what you do not want to be imposed.

j) Be ego-centric and selfish in order to avoid a punishment by the Heaven.

The answer categories were "1) I am proud of it", "2) Don't know (or hard to say)", and "3) I would like to abolish it."

In order to see the general trends on these values, let us consider the differences between the response percentages of category 1 and category 3 . Table 4 shows the percentages in Beijing and Shanghai separately. Besides, the table shows the percentages of the total sample and the elite (defined as before).

Both in Beijing and Shanghai people are proud of their traditional values on "d) diligence and frugality," "h) tolerance, propriety and deference, etc.", and "f) loyalty to the State" whereas they want to abolish the value on "j) egocentricity". The pride in diligence obviously counters against the previously mentioned Weber's argument. Some discrepancy between Beijing and Shanghai may be seen on the value on family: People of Shanghai emphasize "g) parental love, filial piety, glory to ancestors, etc." more than those of Beijing. (Does it mean that people of Shanghai traditionally emphasize the importance of family or that they have become sensitive to family in the face of collapse of traditional family system?) As for the discrepancy between the elite and the total samples, the elite want to abolish the values on "e) farmers should be respected more than merchants" and "c) women's obedience," and they are proud of the traditional value "i) Never impose what you do not want to be imposed" more than the total groups. These may suggest the possible direction for the future of China.

\subsection{Degrees of importance of several disciplines in daily life}

Our questionnaire covers the following items on daily life in general.

a) One's family and children 
Table 5: Degrees of Importance in Daily Life. "Using this scale, where 7 is "very important", and 1 is 'not important at all', can you tell me how much important each of the following are to you?" Each figure shows the percentage on the positive categories $(5,6, \& 7)$ minus the percentage of the negative categories $(1,2, \& 3)$ in the 7 -point scale.

\begin{tabular}{lrr|rr} 
& \multicolumn{2}{c|}{ Beijing } & \multicolumn{2}{c}{ Shanghai } \\
& Total & Elite & Total & Elite \\
\hline one's family & 91.0 & 89.0 & 90.7 & 90.5 \\
work & 86.6 & 87.2 & 85.8 & 92.3 \\
free time (leisure) & 41.8 & 65.0 & 50.6 & 68.9 \\
friends & 70.6 & 71.9 & 65.5 & 66.2 \\
parents, brother, sibling and relatives & 88.5 & 89.1 & 88.0 & 80.3 \\
religion & -69.6 & -66.2 & -45.2 & -42.1 \\
politics & 23.0 & 4.0 & -3.0 & -8.3
\end{tabular}

b) Occupation or work

c) Free time (leisure) and relaxation

d) Friends and acquaintance

e) One's parents, brothers, siblings, and relatives.

f) Religion

g) Politics

The answer categories were a seven-point scale: "1. Not important" to "7.Important."

In order to see the general trends on these values, let us consider the difference between the subtotal of positive categories $5-7$ and the subtotal of negative categories $1-3$ for each item (therefore, the middle category 4 is temporarily ignored.)

Table 5 shows the response percentages in Beijing and Shanghai as well as the percentages for the total sample and for the younger elite as defined before.

In both Beijing and Shanghai, people highly emphasize the importance of "a) one's family", "b) work," and "e) relatives." It may be interesting, however, that there seem some differences between the elite and the total sample in both Beijing and Shanghai with respect to the degree of importance on "free time (leisure)." The elite may emphasize the importance of free time more because they are now satisfied with their work and income (ceiling effect?), or because they are too busy for their current work. It might be interesting to relate the results to some argument against the Weber's thesis on work ethics and capitalism.

As for the importance of "religion," both cities are negative but the degree is less in Shanghai, and there is no significant difference between the younger elite groups and the total samples. This might be related to the recent issue on the new religious movement. (The Chinese is sensitive to the religious movement because they have seen many upheavals by new religious groups in their long history.)

As for the politics, Beijing is on the positive side whereas Shanghai is relatively on the negative side. Also there is a large discrepancy between the total sample and the elite in Beijing on this matter: the discrepancy between the total group and the elite group in each city is much less than that between the total groups in both cities. (We should remember the drastic renovation of political systems undergoing by the central government.) 
Table 6: National Target. "Which of the following do you yourself consider most important in the long run?" (\%)

\begin{tabular}{lrr|rr} 
& \multicolumn{2}{c|}{ Beijing } & \multicolumn{2}{c}{ Shanghai } \\
& Total & Elite & Total & Elite \\
\hline stability of the social (political) order & 36.0 & 34.2 & 28.6 & 22.9 \\
economic stability and growth & 13.4 & 23.7 & 22.9 & 33.1 \\
justice (in politics) & 27.4 & 25.4 & 19.6 & 18.5 \\
fair distribution & 3.3 & 3.1 & 1.6 & 0.6 \\
employment & 13.6 & 9.2 & 18.6 & 19.1 \\
fighting rising prices & 4.0 & 1.3 & 6.5 & 3.2 \\
freedom of speech & 0.9 & 2.2 & 1.2 & 2.5
\end{tabular}

\subsection{National Target}

A question concerning national target was asked as "Which one of the following do you yourself consider most important in the long run?" with the list of items shown in Table 6. This table shows some difference between Beijing and Shanghai with respect to politics and economy. Among others this may be clearly seen in the comparison of the younger elite on "the stability of the social condition" and "the economic stability and growth." The younger elite of Beijing are more concerned with the former whereas the younger elite of Shanghai are with the latter. The higher level of concern is also seen on the "justice in politics (more explicitly, fighting against corruption and promoting integrity) for both the younger elite and the total sample in Beijing".

There is some discrepancy between the younger elite and the total sample in Beijing on "the employment" and "the economic stability and growth": the elite are concerned with the economy and growth of the state whereas the ordinary people are concerned more with one's own employment. This reflects the fact that the socialist state has been now producing many unemployed workers since 1997 or so in their shift to capitalism.

As for the formal declaration of national target, one should see the Tenth Five-Year Plan approved by the People's Assembly of March 2001. One of the main parts was the realization of the rapid advancement of science and technology in various areas including economy, daily life, military, and transportation, as well as economic prosperity.

\subsection{Anxiety}

Table 7 shows the data on people's sense of anxiety. The question was "To what extent do you worry, either for yourself or for your family, about each of the following? Would you say very much, somewhat, slightly, or not at all?"

People in both Beijing and Shanghai were very much concerned with unemployment, but the elite groups' sense of anxiety was lower than that of the total sample. As for serious illness, only Shanghai showed their anxiety. This may remind us of the frequent propagation of epidemic diseases such as AIDS or SARS at the region in their long history, although the survey was conducted before the occurrence of SARS. The way of fighting with SARS by the local governments was criticized because they are suspected to hide the seriousness of the disease and the propagation. On the other hand, it should be noted that their anxiety with war was lowest than with any other item in the list. This seems to 
Table 7: Anxiety: "To what extent do you worry, either for yourself or for your family, about each of the following? Would you say very much, somewhat, slightly, or not at all?" Each figure shows the percentage of combined categories "very much" and "somewhat." (The remaining categories are "a little bit" and "not at all.")

\begin{tabular}{lrrrr}
\hline & \multicolumn{2}{c}{ Beijing } & \multicolumn{2}{c}{ Shanghai } \\
& Total & Elite & Total & Elite \\
\hline Serious illness & 69.1 & 71.5 & 73.7 & 56.7 \\
Traffic accident & 65.4 & 66.7 & 67.5 & 60.6 \\
Unemployment & 52.8 & 39.9 & 62.2 & 54.8 \\
War & 45.3 & 41.7 & 43.0 & 45.2 \\
Nuclear plant accident & 45.6 & 49.5 & 37.7 & 40.7 \\
\hline Multiple Total \% & 279.9 & 269.3 & 284.1 & 258.0 \\
\hline
\end{tabular}

reflect the critical situation in the current China. China is now rapidly transforming itself and probably will exemplify another successful "capitalist" country of Asia in the near future. Although a sort of military or political tension between the mainland of China and Taiwan (or other neighboring countries) frequently occurs, it is not surprising that China avoids a serious conflict in order to maintain their economic development which necessitates the social order in the Asia.

\section{Sense of Trust}

The last two decades have seen extensive studies on "trust" in the aftermath of cold war. It is now the time to reconsider how we can develop international trust in order to prevent conflicts between different countries, races, or religious groups released from the control of the political ideologies of old world system.

There may be various possible definitions of "trust" (see Hosmer, 1995). For example, Zucker (1986) classified three ways of trust production: 1) process-based trust tied to past exchanges, 2) characteristic-based trust tied to personal characteristics, such as family background and ethnicity, and 3) institutional-based trust tied to formal societal structures. Although Shapiro (1987) criticized the third category because he believes that trust cannot be institutionalized, it would be possible that institutions such as a legal system can function where people cannot rely on interpersonal trust. This was actually happened in the time of industrial revolutions. It may be important to note that the Chinese government is attempting to shift itself from the leader-oriented regime in the past decades to more legislation-oriented social system.

In his comparative economic theory, Fukuyama (1995) focused on of trust as a property of national character, and contrasted Japan, USA and Germany as highly trustful countries with China, France, and Italy as less trustful countries. In the above-mentioned paper, Zucker questioned on the direct scalability of subjective trust. Although it might be questionable whether trust can be directly measured or not, people's responses in questionnaire surveys must provide us with some information on their sense of trust in a certain way if adequate items are chosen and response data are adequately analyzed.

Three items have been used to scale people's sense of trust by the Institute of Social Research at the University of Michigan in their survey on "Americans' Quality of Life" 
(NORC-ROPER, 1986) or in GSS (General Social Survey). The three items of GSS trust scale were stated as follows.

a) Would you say that most of the time, people try to be helpful, or that they are mostly just looking out for themselves?
1. Try to be helpful,
2. Look out for themselves,
3. Other (PLEASE SPECIFY)
4. Don't know.

b) Do you think that most people would try to take advantage of you if they got the chance, or would they try to be fair?
1. Take advantage,
2. Try to be fair,
3. Other (PLEASE SPECIFY),
4. Don't know.

c) Generally speaking, would you say that most people can be trusted or that you can't be too careful in dealing with people?
1. Can be trusted,
2. Can't be too careful,
3. Other (PLEASE SPECIFY),
4. Don't know.

Our survey of the Japanese National Character also has adopted the three items since 1978 for the Japan Survey (Yoshino, 2002a).

Miyake analyzed the trust scale of GSS in our seven nation survey (Hayashi et al., 1998, Ch.7), and he found the following.

1) People with some religious faith, whatever it is, have more sense of trust.

2) In the western countries, there is a weak correlation between sense of trust and income, and education level.

3) Women are more optimistic than men in all the seven countries.

As to the correlation between income and education levels in the Western world, we did not necessarily find such a correlation in the Asia. Banfield (1958)'s claim that "distrust is the culture of the poverty" may not necessarily be applicable to the Eastern people (Yoshino, 2002a). These observations must be closely connected to the extent of applicability of the GSS items as a trust scale in cross-national comparative studies (Yoshino, 2003).

Yoshino reported (2002a, Fig. 1; 2003) about the stability of rate of the Japanese who chose optimistic categories in all three items ("1", "2" \& "1" of items a, b \& c). (I frequently use the rate as a trust scale thus defined, although there may be some other possible definitions of a trust scale based on the three items. For example, it is possible to use the average of respondents' scores where 1 point is assigned to each of the optimistic categories. I have, however, confirmed the consistency between the two scales: the trend is not changed so much, whichever one of these scales is used. For another example, it is possible to use the three items as independently. I have found, however, that items a \& b are closely correlated in the USA whereas items b \& c are closely correlated in Japan.) As far as this particular trust scale is concerned, the Japanese people's sense of trust has not shown a remarkable change at least over the last two decades. This is a piece of evidence that attitudes and values on interpersonal relationships are relatively stable over years.

Our survey shows the percentages of those who chose all three optimistic categories in several countries or regions: the non-Japanese (41.2\%) and the Japanese $(40.8 \%)$ in 
Table 8a: Trust and Age. The older has the higher sense of trust in Beijing, whereas the middle age (the generation of Cultural Great Revolution) has the lower sense of trust than the younger and the older generations in Shanghai. (The figures of Table 8 show the percentages of those who chose optimistic categories in all three items of GSS trust scale. See the text.)

\begin{tabular}{lll} 
Age & \multicolumn{2}{c}{ City } \\
(years old) & Beijing & Shanghai \\
\hline $18-39$ & 13.6 & 24.5 \\
$40-55$ & 16.5 & 17.1 \\
$56-$ & 22.0 & 26.0
\end{tabular}

Table 8b: Trust and Education. There seems no significant difference between educational levels.

City

\begin{tabular}{lll} 
School & Beijing & Shanghai \\
\cline { 1 - 2 } Primary/Secondary & 16.5 & 18.6 \\
High & 16.9 & 21.0 \\
College/Graduate & 18.0 & 24.0
\end{tabular}

Table 8c: Trust and (self-reported) Family Income. There seems no significant difference in sense of trust between categories of family income in Beijing, whereas the middle category showed higher rate in Shanghai.

\begin{tabular}{lll} 
& \multicolumn{2}{c}{ City } \\
Family Income (Chinese Yen) & Beijing & Shanghai \\
\cline { 1 - 2 } Uppe $(>40,000)$ & 21.0 & 18.5 \\
Middle $(20,000-40,000)$ & 18.1 & 24.7 \\
Lower $(<20,000)$ & 17.5 & 18.4
\end{tabular}

Table 8d: Trust and (self-reported) Social Class. There seems no significant difference between social classes.

\begin{tabular}{lll} 
& \multicolumn{2}{c}{ City } \\
Social Class & Beijing & Shanghai \\
\cline { 1 - 2 } Upper & 16.8 & 20.2 \\
Middle & 17.4 & 23.1 \\
Lower & 16.6 & 17.1
\end{tabular}

Hawaii, the USA (26.6\%), Britain (23.6\%), the West Germany (21.7\%), Shanghai $(20.1 \%)$ and Beijing (17.1\%), the Netherlands (16.7\%), Japan (13.3\%), France (6.5\%), Italy $(5.2 \%)$, and the Japanese Brazilian (4.2\%). Note that the two cities of China are located in the middle of the ranking. This may be against Fukuyama's thesis previously mentioned (1995). There are some alternative interpretations for it. One is that Fukuyama is wrong on this regard. Another interpretation is that the scale may not be adequate for the cross-national comparison. The validity of scale and the object to scale have a complementary relationship, therefore, we need to carefully analyze the results with substantive data from various perspectives. Even if a certain scale is not valid for direct cross-national comparison, however, it may be still valid for domestic comparison (as a relative scale) in each country.

Here it seems worthwhile analyzing more details of Chinese data on this scale as in Table 8a, b, c, and d. These tables show cross-tabulation of sense of trust with respect to age, educational level, (self-reported) family income, and (self-reported) social class. 
Table 9: Attitudes towards Political Leaders. "The best way to improve the country is for the people to leave everything to statesmen, rather than for the people to discuss things among themselves. Do you agree with this or disagree?"

\begin{tabular}{|c|c|c|c|c|c|c|c|}
\hline & \multicolumn{3}{|c|}{ Beijing } & \multicolumn{3}{|c|}{ Shanghai } \\
\hline & & "agree" & "disagree" & $\begin{array}{l}\text { "depends } \\
\text { on case" }\end{array}$ & "agree" & "disagree" & $\begin{array}{l}\text { "depends } \\
\text { on case" }\end{array}$ \\
\hline \multirow[t]{2}{*}{ Gender } & $\mathrm{M}$ & 27.9 & 42.7 & 26.1 & 21.3 & 36.7 & 37.4 \\
\hline & $\mathrm{F}$ & 28.4 & 39.5 & 26.8 & 24.2 & 36.1 & 35.9 \\
\hline \multirow[t]{7}{*}{ Age } & -19 & 10.8 & 64.9 & 24.3 & 15.8 & 52.6 & 21.1 \\
\hline & $20-$ & 20.4 & 48.0 & 28.3 & 18.4 & 38.0 & 41.1 \\
\hline & $30-$ & 30.3 & 32.1 & 32.1 & 26.1 & 32.6 & 39.1 \\
\hline & 40 & 35.7 & 37.5 & 23.8 & 24.0 & 32.5 & 37.1 \\
\hline & $50-$ & 30.5 & 42.7 & 23.8 & 25.4 & 36.5 & 34.6 \\
\hline & $60-$ & 22.0 & 44.5 & 26.4 & 22.1 & 36.1 & 39.3 \\
\hline & $70+$ & 29.0 & 41.9 & 22.6 & 14.5 & 53.2 & 27.4 \\
\hline \multirow{6}{*}{ Education } & NA/Others & 20.0 & 20.0 & 20.0 & 42.9 & 21.4 & 28.6 \\
\hline & Elementary school & 36.9 & 40.8 & 15.4 & 33.9 & 27.4 & 32.3 \\
\hline & Middle School & 32.6 & 39.0 & 25.0 & 23.6 & 31.1 & 39.9 \\
\hline & High School & 29.1 & 39.1 & 25.5 & 22.5 & 37.6 & 36.4 \\
\hline & College & 20.1 & 45.0 & 33.1 & 17.3 & 45.7 & 35.8 \\
\hline & Graduate School & 30.8 & 38.5 & 30.8 & 18.2 & 72.7 & 9.1 \\
\hline \multirow{6}{*}{$\begin{array}{l}\text { Income } \\
\text { (personal } \\
\text { yearly } \\
\text { income) }\end{array}$} & Less than 10000 Yuan & 31.0 & 39.1 & 24.9 & 23.8 & 32.6 & 38.0 \\
\hline & 10001-20000 Yuan & 25.8 & 43.2 & 27.1 & 20.4 & 38.7 & 39.6 \\
\hline & 20001-30000 Yuan & 20.9 & 45.1 & 33.0 & 20.3 & 46.1 & 28.1 \\
\hline & 30001-40000 Yuan & 14.3 & 47.6 & 38.1 & 22.9 & 45.7 & 25.7 \\
\hline & More than 40000 Yuan & 41.7 & 33.3 & 25.0 & 20.5 & 43.6 & 35.9 \\
\hline & $\mathrm{DK} / \mathrm{NA}$ & 24.2 & 42.4 & 25.8 & 32.0 & 24.0 & 36.0 \\
\hline
\end{tabular}

Note that the response data of item b) of GSS scale show a low inverse-correlation between sense of trust and education level, as well as income: the higher education level shows the lower trust; the higher income shows the lower trust.

Although we were not allowed to ask sensitive questions concerning politics and religion in China, we included an item concerning a trust on politics in our questionnaire. The question was "Some people say that the best way to improve the country is for the people to leave everything to statesmen, rather than for the people to discuss things among themselves. Do you agree with this, or disagree?" (The original wording was: "Some people say if we get outstanding political leaders, the best way to improve the country is for the people to leave everything to them, rather than for the people to discuss things among themselves. Do you agree with this, or disagree?" Unfortunately, the question was re-worded by a local supervisor of the survey in Beijing as mentioned above, and it injured cross-national comparability with our past survey data. This is an example of limitation that we face in surveying political attitudes in the current China. For another remark, note that the Chinese wording is ambiguous about the distinction between singular and plural, such as "statesman" and "statesmen".)

Overall, for people of any age, any educational level, and any occupation, the rate of "disagree" to the above-mentioned question is larger than that of "agree." At this point of research, I am not sure as to whether the result should be interpreted as distrust to politicians or as a change of the China from the virtue-governing system (a government by virtuous leader as a Confucius ideal, but it often tends to be a personality cult in reality) 
to a democratic state where people have good critical spirit.

\section{Concluding Remarks - The World as a Cultural Manifold-}

The 20th century was the time of expansion of western civilization. Differences of cultures occasionally prevented us from our mutual understanding each other. In this time of globalization, I would like to emphasize the fact that there are various ways of successful social development; therefore, we should not impose one's own social value on any other country if we intend to develop a peaceful world.

The globalization necessarily changes some institutional systems and customs towards more universal ones under the influences of transnational exchange or trade. On the other hand, some other systems are becoming more and more sensitive to cultural differences, as a reaction to the globalization.

In order to facilitate the mutual understanding between the East and the West, we need to keep in mind the differences of social values between them. The study on the scale of trust (Fig. 4) may caution us on the applicability of a certain "single" scale invented by the Western cultures to the Eastern cultures, or vice versa. For example, it is not always the case in the Asia that "the distrust is a culture of the poverty" as Banfield (1958) once mentioned. A Chinese proverb says that "Fine manners need a full stomach" (or "The belly has no ears"), but another says "Be contended with honest poverty." Gallup (1977, p.461) reported that they could not find a very poor but still happy people in their global survey. I think that they missed the reality. For example, Brazilians were very optimistic even when Brazil fell down to the worst debtor nation in the world (Inkeles, 1997). Inglehart reported a correlation of .57 between economic development and life satisfaction for some 20 countries surveyed in 1980s (Inkeles, 1997, p.366-371). But the life satisfaction of Japan in the 1980's was lower than 2000, although Japan was close to the top of the world economy in those days and she has been suffering from depression over years until recently. Thus, we need scales constructed from various perspectives or social values in order to understand various cultures in the age of globalization.

Although China had so many battles between small countries (within the area corresponding to the modern China) over thousands years in their history, once they were synthesized as a large empire, their government employed peoples of various races as high class bureaucrats. This made them possible to develop and maintain a large empire and their culture, often over centuries. This is analogous to the Roman Empire, but it is contrastive to the modern western countries (and Japan during WWII) that colonized Asian and African countries in the 19th and 20th centuries. The history shows that trust between different races changes according to social conditions in the long run, although it is relatively stable over time.

After our China survey mentioned in this paper, there occurred the problem of SARS propagating from Guang-Zhou in China. People inside and outside China criticized the local governments, suspecting that they attempted to hide the serious conditions. This seems to suggest a significant change of China, from secretive attitude to more open attitude for every matter. The secretive attitude was linked to the system of severe punishment 
on political responsibility. The open attitude is a key to democracy that is necessary for successful capitalism. The mayor of Beijing got fired because of his ill treatment with SARS. The government started encouraging people to inform of the presence of the patients. This situation seems to show that China is changing rapidly, but in a Chinese way. Here it may be important to quote Dogan (2000)'s statement “...Erosion of confidence is first of all a sign of political maturity. It is not so much that democracy has deteriorated, but rather the critical spirit of most citizens has improved..."

In spite of prevailing confusion in the East Asia (actually in the entire world), I hope that the East Asia will advance towards the peaceful development without serious conflicts. For the mutual understanding with Asian countries, one should keep in mind their ways of thinking such as "Mentsu (face)" and "Honne and Tatemae (real intension and principle)" of the Chinese, the Japanese, and the Korean. This is also the case with the Asian countries for the understanding of the west.

Once upon a time, Weber (1904-05) argued that Asian countries were not able to develop capitalism in his theory on religion and capitalism. Now we know so many counterexamples such as Japan, Korea, NIES, and China, against his argument. Some people argued that the Japanese adaptation of Confucius philosophy adapted to Japan functioned as a replacement of Protestant ethics and lead Japan to a successful development of capitalism (Morishima, 1984). But the past decades have seen many examples to show that economic success is not linked to a particular religion. Now we have more and more data to consider the relationships between economic development, social systems and social values because of the rapid change of social systems in many countries over the world than before.

I hope that our survey data will be helpful for the further constructive arguments and the mutual understanding for the peaceful development of Asia.

\section{REFERENCES}

Banfield, E.C. (1958). The moral basis of a backward society. The Free Press: NY.

Dogan, M. (2000). Deficit of confidence within European democracies. In Haller, M. (Ed.), The making of the European union (pp.243-261). Springer-Verlag: Paris.

Fukuyama, F. (1995). Trust. Free Press: NY.

Gallup, G.H. (1977). Human needs and satisfactions: a global survey. Public Opinion Quarterly, winter, 459-467.

Hayashi, C. (Ed.) (1973). A study of Japanese-Americans in Honolulu, Hawaii (in Japanese). ISM Research Report General Series, No.33. ISM: Tokyo.

Hayashi, C. (1992). Suuryou-ka [Hayashi's quantification method]. Asakura-syoten.

Hayashi, C. (2001). De-ta no kagaku [The Science of Data]. Asakura-syoten: Tokyo.

Hayashi, C., Yoshino, R., Suzuki, T., Hayashi, F., Kamano, S., Miyake, I., Murakami, M., \& Sasaki, M. (1998). Kokuminsei nanaka-koku hikaku [cross-national comparison of seven nations]. Idemitsu-syoten: Tokyo.

Hosmer, L.T. (1995). Trust: the connecting link between organizational theory and philosophical theory. Academy of Management Review, 20, 2, 379-403.

Inkeles, A. (1997). National character. Transaction: New Brunswick.

Mizuno, K., Suzuki, T., Sakamoto, Y., Murakami, M., Nakamura, T., Yoshino, R., Hayashi, C., Nishihira, S., \& Hayashi, F. (1992). Dai 5 nihonjin no kokuminsei (Japanese national 
character V) (in Japanese). Idemitsu syoten: Tokyo.

Morishima, M. (1984). Why has Japan succeeded? (in Japanese). TBS Britannica: Tokyo.

NORC-ROPER (1986). General social surveys, 1972-1986: cumulative codebook. The Roper Center for public opinion research, University of Connecticut.

Sakamoto, Y., Nakamura, T., Tsuchiya, T., Maeda, T., \& Fouse, D.B. (Eds.) (2000). A study of the Japanese national character: the tenth nationwide survey (1998). ISM Research Report, General Series, No.85.

Sengoku, T., \& Qian, O. (1992). Social values and life style in China today. The Simul Press: Tokyo.

Tolstoy, L. (1878). Anne Karenina. Translated by R.S. Townsend (1958). J.M. Dent \& Sons. Ltd.

Weber, M. (1904-05). Protestant ethics and sprit of capitalism [translated by T. Parsons]. Routledge Classics.

Yoshino, R. (1992a). Superculture as a frame of reference for cross-national comparison of national characters. Behaviormetrika, 19, 1, 23-41.

Yoshino, R. (1992b). The unbiased BIGHT model and its application to the analysis of responses of national characters. Behaviormetrika, 20, 2, 171-186.

Yoshino, R. (Ed.) (1995). A handbook of cross-national comparative survey. ISM Research Report No.77. ISM: Tokyo.

Yoshino, R. (Ed.) (2001a). A study of statistical science on cultural transmission based on social survey data of National Character. A report submitted to The Ministry of Education, Culture, Sports, Science \& Technology.

Yoshino, R. (Ed.) (2001b). Hawaii Resident Survey 1999-2000. The ISM Research Report, No.86. ISM: Tokyo.

Yoshino, R. (2001c). Kokoro wo hakaru [Measuring the mind]. Asakura-syoten: Tokyo.

Yoshino, R. (2002a). A time to trust - a study on peoples' sense of trust from viewpoint of crossnational and longitudinal survey on national character-. Behaviormetrika, Vol.29, No.2, 231-260.

Yoshino, R. (2003). Shinrai no toki (A time to trust) [in Japanese]. Eco-Forum, Vol.22, No.1, a special issue on social capital II, 42-51.

Yoshino, R. (2005a). Higashi-Ajia kati-kan tyousa-bunnka tayoutai-kaiseki ni motozuku keiryoteki bunmeiron koutiku ni mukete- (East Asia Value Survey - For the development of Behaviormetric study of civilization on the Cultural Manifold Analysis (CULMAN) [in Japanese]. Japanese Journal of Behaviormetrika, Vol.32, No.2, 133-146.

Yoshino, R. (2005b). Trust and national character: Japanese sense of trust, cross-national and longitudinal surveys. Comparative Sociology, Vol.4, No.3-4, 417-450.

Yoshino, R., \& Hayashi, C. (2002b). An overview of cultural link analysis of national character. Behaviormetrika, Vol.29, No.2, 125-141.

Zheng, Y. (Ed.) (2002). Researches on the national character of Chinese and Japanese-A sampling srvey in Beijing, China-. ISM Research Report No.89.

Zheng, Y. (2003). Researches on the national character of Chinese and Japanese-A sampling survey in Shanghai, China-. ISM Research Report No.90.

Zheng, Y., \& Yoshino, R. (2002). The sampling methods for the China survey (Beijing and Shanghai) [in Japanese]. Proceedings of the 30-th conference of Japan Behaviormetric Society, 346-349.

Zheng, Y., \& Yoshino, R. (2003). For the comparative study of East Asia value survey (in Japanese). The Japanese Journal of JAPOR [Japanese Association of Public Opinion Research], Vol.91, 16-21.

Zucker, L.G. (1986). Production of trust: institutional sources of economic structure, 1840-1920. Research in Organizational Behavior, 8, 53-111. 